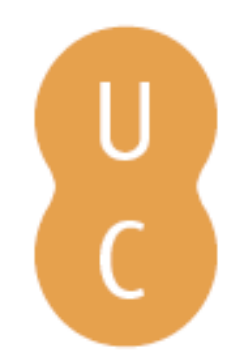

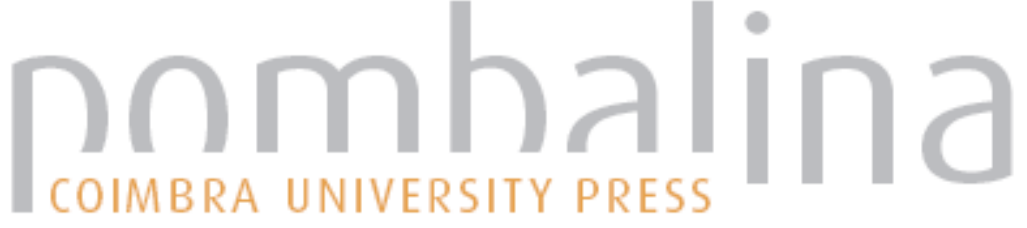

Woody Allen ou a ficção como jogo: o caso Zelig

Autor(es): Reis, Carlos

Publicado por: Imprensa da Universidade de Coimbra

URL

persistente: URI:http://hdl.handle.net/10316.2/41343

DOI: $\quad$ DOI:https://doi.org/10.14195/978-989-26-1324-6_1

Accessed : $\quad$ 26-Apr-2023 09:16:27

A navegação consulta e descarregamento dos títulos inseridos nas Bibliotecas Digitais UC Digitalis, UC Pombalina e UC Impactum, pressupõem a aceitação plena e sem reservas dos Termos e Condições de Uso destas Bibliotecas Digitais, disponíveis em https://digitalis.uc.pt/pt-pt/termos.

Conforme exposto nos referidos Termos e Condições de Uso, o descarregamento de títulos de acesso restrito requer uma licença válida de autorização devendo o utilizador aceder ao(s) documento(s) a partir de um endereço de IP da instituição detentora da supramencionada licença.

Ao utilizador é apenas permitido o descarregamento para uso pessoal, pelo que o emprego do(s) título(s) descarregado(s) para outro fim, designadamente comercial, carece de autorização do respetivo autor ou editor da obra.

Na medida em que todas as obras da UC Digitalis se encontram protegidas pelo Código do Direito de Autor e Direitos Conexos e demais legislação aplicável, toda a cópia, parcial ou total, deste documento, nos casos em que é legalmente admitida, deverá conter ou fazer-se acompanhar por este aviso.

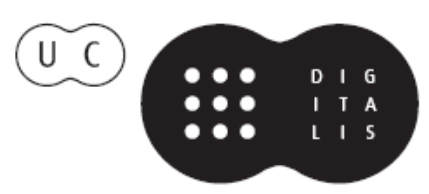





\section{WOODY ALLEN OU A FICÇÃO COMO JOGO: \\ O CASO ZELIG}

Carlos Reis

Centro de Literatura Portuguesa/UC

1. Alguns tópicos de reflexão, ainda em jeito de abertura. Assim: se falamos da narrativa e do conhecimento que ela permite, falamos também de um modo discursivo cujo projeto fundamental é eliminar aquilo que de transitório e fugaz existe nas ações humanas; pela narrativa conferimos estabilidade discursiva a essas ações (que são ações de mudança e em mudança) e procuramos dar sentido a acontecimentos que, aquém da elaboração narrativa, parecem dispersos e desarticulados.

Por outro lado, uma realidade vivida por entidades humanas pode ganhar autonomia, quando a configuramos e a lemos como ficção: a ficção é, então, condição para a transcendência (como quem diz, para uma certa forma de permanência transnarrativa) daquilo que eventualmente decorre de experiências de vida concretas. Daí podermos afirmar que atingimos um certo nível de conhecimento através da narrativa: conhecimento de atos dos homens, de experiências de vida, de situações sociais e mentais, etc. Esse conhecimento não é posto em causa pela condição ficcional das narrativas, sendo certo, contudo, que essa condição solicita atitudes cognitivas, culturais e emotivas específicas, em grande parte relacionadas com aquilo 
a que generalizadamente chamamos, desde a famosa postulação de Coleridge, suspensão voluntária da descrença.

O cinema de Woody Allen e o filme Zelig encenam, de forma extremamente sugestiva, os termos em que a ficção se exibe como jogo, sem que assim se ponha em causa o potencial de conhecimento que ficou referido. Conhecimento narrativo de um fenómeno efémero e, adianto desde já, busca de sentido e de prolongamento no tempo daquele fenómeno, como exemplaridade a reter. É assim que em Zelig leremos uma tentativa (brilhante, a meu ver) de, pela narrativa, se proceder a uma exegese do mundo; no caso em apreço, esse mundo é o de um sujeito apresentado como figura real, que dá pelo nome de Leonard Zelig.

2. Antes de chegar a Zelig, farei um desvio por várias questões que nele estão implicadas, dizendo respeito, em geral, às respostas que é possível encontrar para a pergunta: como reconhecemos uma narrativa, quando a lemos (ou quando a ouvimos; ou quando a vemos)? Se tal fosse possível, neste local e neste momento, aquelas respostas seriam apoiadas por uma reflexão acerca de diversos aspetos da existência e do funcionamento das narrativas, no plano material e no plano semiodiscursivo. De modo que faço aqui um inevitável bypass que deixa em aberto, talvez para outra altura, indagações em torno do canal de comunicação narrativa (visual, auditivo, tátil), dos suportes e da sua especificidade (incluindo a distinção analógico/ digital), das linguagens de enunciação (verbal, verbo-icónica) e também dos efeitos cognitivos deduzidos destas escolhas. Não deixo, contudo, de assinalar que os trabalhos de Marie-Laure Ryan são, neste e noutros domínios, de muito boa ajuda (cf. Ryan (ed.), 2004; Ryan, 2006; Ryan e Thon (eds.), 2014).

Reconhecer uma narrativa é, antes de mais, aderir a uma sua propriedade nuclear, a narratividade, em dois planos que podem ser conjugados. No plano da funcionalidade discursiva, a narratividade 
é entendida como um "conjunto de propriedades que caracterizam a narrativa e que a distinguem da não-narrativa", correspondendo aquelas propriedades às "características formais e contextuais que fazem de um texto (narrativo) mais ou menos narrativo" (Prince, 2003: 65). Para além deste plano funcional (que é basilar, mas deve ser alargado), a narratividade concretiza-se como experiência humana com um certo índice de naturalização, numa abordagem que é já de feição cognitivista.

A chamada narratologia natural contempla este campo de análise e argumenta que a "narratividade é uma função dos textos narrativos e centra-se numa experiencialidade de natureza antropomórfica" (Fludernik, 1996: 26). Nesta aceção, faz sentido falar em narrativização como princípio de interpretação e como estratégia de leitura; uma tal estratégia de leitura narrativística compensa as inconsistências e as incompletudes de uma narrativa (porque ela nunca conta tudo) pelo recurso a esquemas narrativos previamente naturalizados, com base na nossa experiência empírica e nas práticas narrativas que a cada momento ela propicia. Daqui chegamos a um conceito ao mesmo tempo elementar e muito aberto de narrativização, como processo que convoca a narratividade: a narrativização é "a leitura dos textos como narrativos, como constitutivos de narratividade no processo de leitura" (Fludernik, 1996: 20). A abertura pan-narrativista que daqui se infere é evidente: para além do que lemos na prosa narrativa, a narratividade está disseminada na poesia e nos textos dramáticos e pode ser nuclear em discursos verbais, icónicos e verbo-icónicos que encontramos no cinema, na televisão, na imprensa, etc. (veja-se Prince, 2005; Abbott, s.d.).

3. Antes de chegarmos a Zelig, recordemos alguns antecedentes e desenvolvimentos possíveis. Os antecedentes do que fica dito estão no pensamento e nas propostas de Roland Barthes, explanado num número hoje histórico (porque fundacional) da revista Communications. 
No seu texto de abertura (e no seu incipit, lugar de destaque, tal como acontece em certas narrativas), Barthes escreveu:

Inumeráveis são as narrativas do mundo. Há em primeiro lugar uma variedade prodigiosa de géneros, distribuídos entre substâncias diferentes, como se toda matéria fosse boa para que o homem lhe confiasse as suas narrativas: a narrativa pode ser sustentada pela linguagem articulada, oral ou escrita, pela imagem, fixa ou móvel, pelo gesto ou pela mistura ordenada de todas estas substâncias; está presente no mito, na lenda, na fábula, no conto, na novela, na epopeia, na história, na tragédia, no drama, na comédia, na pantomima, na pintura (...), no vitral, no cinema, nas histórias em quadradinhos, no fait divers, na conversação (Barthes, 1966: 1).

O que veio depois e pudemos ler nos trabalhos inspirados pela análise estrutural da narrativa (logo naquele número de Communications, mas não só nele) e pela narratologia de inspiração genettiana dos anos 70 e 80 é sabido e não precisa de ser lembrado, a não ser para sublinhar o seguinte: no tocante aos estudos narrativos, ao seu potencial operatório e às bases epistemológicas em que eles se sustentam, não estaríamos onde estamos sem o contributo daqueles trabalhos.

Depois deles e episodicamente em diálogo com eles, a filosofia da narrativa plasmada nos magistrais estudos consagrados por Paul Ricoeur ao tempo narrativo abriu caminhos de reflexão hermenêutica que encontramos sintetizados na "hipótese de base" que rege o trabalho do grande pensador francês. Diz Ricoeur, num dos volumes de Temps et récit: "Existe entre a atividade de contar uma história e o caráter temporal da experiência humana uma correlação que não é puramente acidental, mas apresenta uma forma de necessidade transcultural." E acrescenta: "o tempo torna-se tempo humano na medida em que é articulado em modo narrativo, e (...) a narrativa 
atinge a sua significação plena quando se torna uma condição da existência temporal" (Ricoeur, 1983: 85).

Sintomaticamente, é também a experiência humana que aparece invocada no ensaio em que Jerome Bruner conjuga psicologia cognitiva e teoria da aprendizagem. Entendendo as narrativas como uma versão da realidade suportada por aquilo a que chama "necessidade narrativa", Bruner nota: "Organizamos a nossa experiência e a nossa memória dos acontecimentos humanos principalmente em forma narrativa - histórias, desculpas, mitos, razões para fazer e para não fazer e assim por diante" (Bruner, 1991: 4) 3 $^{3}$ O que nos traz de volta à naturalização da narrativa de que anteriormente falei. Toda a narrativa constitui, em suma, um procedimento alargado, consistente e consequente de construção de sentido, com uma dimensão humana e com um "formato" temporal que são reversíveis e interativos. Derivadamente, a narrativa traduz um impulso de prolongamento daquilo que parece transitório e contingente; a isto junta-se a sua capacidade de modelização secundária ${ }^{4}$ de ações humanas, de acordo com a condição ficcional (que é também uma condição narrativa) da personagem e com o processo de figuração que ela implica.

É pela narrativa ficcional (e em particular pela narrativa ficcional literária) que tentamos resolver a tensão entre autonomia e heteronomia que é própria das práticas artísticas. Lemos as ficções narrativas literárias como representações autónomas de experiências humanas que, de facto, nos são alheias, no plano empírico; mas ao mesmo tempo, persistimos em ler essas ficções porque reconhecemos nelas

\footnotetext{
${ }^{3}$ Acrescenta Bruner: "As narrativas são, então, uma versão da realidade cuja aceitabilidade é regida por convenção e por 'necessidade narrativa', mais do que por verificação empírica e exigência lógica, embora ironicamente não tenhamos escrúpulo em chamar às histórias verdadeiras ou falsas" (Bruner, 1991: 4-5).

${ }^{4}$ A modelização secundária que a narrativa literária concretiza "opera com as fundamentais categorias da narrativa, do tempo ao modo, passando pela personagem, pela representação do espaço e pela estruturação da ação" (Reis e Lopes, 2011: 236).
} 
uma evidente dinâmica de pervivência daquilo que nelas é dito e vivido por "pessoas de livro"'.

Sendo em princípio localizados e contingentes, esses atos e essas palavras reacendem, no nosso tempo e nas nossas vidas, sentidos que, por fim, transcendem as ficções narrativas em que se encontram disponíveis, para com elas interagirmos. Não cavalgamos Rocinante, em investida contra moinhos de vento, nem tentamos impedir Dom Quixote de o fazer (deixamos isso por conta de Sancho Pança); mas aquele gesto supostamente tresloucado continua a convocar as nossas emoções, quando a ele reagimos, com solidária cumplicidade ou com risonha compreensão. A vida da obra (Ingarden dixit) e a decorrente sobrevida das personagens são, afinal, da mesma natureza daquela perenidade artística que Eça ilustrou com uma história de amor (com uma narrativa) chamada Romeu e Julieta: "Shakespeare está realmente tão vivo como quando, no estreito tablado do Globe, ele dependurava a lanterna que devia ser a lua, triste e amorosamente invocada, alumiando o jardim dos Capuletos" (Queirós, 2009: 201).

4. O cinema de Woody Allen envolve, com frequência, temas e motivos literários que são bem notórios. Recordo os títulos da sua extensa filmografia que, neste aspeto, são mais significativos. Aqueles temas emergem, em registo de alusão, de paródia ou de reescrita cinematográfica, em Manhattan (1979), em Uma Comédia Sexual numa Noite de Verão (1982) ou em Balas sobre a Broadway (1994). Não apenas metaliterária, mas também de índole metanarrativa é a conceção e a realização de outros filmes, sobretudo das décadas de 80 e 90, a saber: Zelig (1983), A Rosa Púrpura do Cairo (1985), Os Dias da Rádio (1987), Poderosa Afrodite (1995), As faces de Harry (1997) e ainda o mais tardio Melinda e Melinda (2004) ${ }^{6}$.

\footnotetext{
${ }^{5}$ A expressão "pessoas de livro" encontra-se num passo da História do Cerco de Lisboa, de José Saramago ("pessoas de livro são personagens, contrapôs Maria Sara").

${ }^{6}$ Refiro os títulos dos filmes pela designação que receberam em Portugal.
} 
São sobretudo estes filmes que convidam a uma integração de questões e problemas do âmbito dos estudos narrativos com questões e problemas do âmbito dos estudos mediáticos e, mais especificamente, do campo das relações entre narrativa literária e narrativa cinematográfica. O que requer uma ressalva metodológica importante: sem privilegiar uma leitura de especialidade da narrativa cinematográfica, a análise que me proponho realizar orienta-se para a problematização de aspetos compositivos e de categorias (por exemplo, a personagem), cuja dilucidação poderá ser muito fecunda para o estudo da narrativa, em termos alargados. É nesse sentido que a filmografia de Woody Allen, com toda a evidência, é exemplarmente rica. ${ }^{7}$

Menciono de seguida, e apenas em termos introdutórios, algumas daquelas questões a que chamo paraliterárias e paranarratológicas. Assim:

i. As fronteiras da ficção e o seu estatuto ontológico, bem como a relevância da metalepse e a diluição dos limites dos universos ficcionais, como se vê em A Rosa Púrpura do Cairo ("é tudo uma questão de semântica", diz uma das personagens).

ii. A relação entre ator e personagem ou os condicionamentos do casting, em relação direta com a sobrevida das figuras ficcionais; incluem-se aqui as determinações extra-artísticas e as perversões do dito casting (veja-se Balas sobre a Broadway e, de novo, A Rosa Púrpura do Cairo).

iii. Os processos de figuração da personagem, em relação direta com géneros literários, com as suas injunções representacionais e com os seus efeitos cognitivos (por exemplo, em Melinda $e$ Melinda).

\footnotetext{
${ }^{7}$ No plano pedagógico, a integração a que me referi (estudos narrativos e estudos mediáticos) aconteceu no seminário Estudos Narrativos Mediáticos, que lecionei no doutoramento em Ciências da Comunicação da Faculdade de Letras de Coimbra.
} 
iv. As condições de existência semiodiscursiva dos relatos noticiosos e ficcionais no espaço mediático, bem como os efeitos cognitivos e sociais que decorrem delas e das suas personagens (em Os Dias da Rádio).

v. A relação da personagem e da sua construção com as decisões (ou com as suas limitações) do escritor (As faces de Harry), bem como o peso de mitos ancestrais e de uma tradição cultural em revisão paródica (Poderosa Afrodite).

Quem se lembra de Zelig ou pôde visioná-lo recentemente terá bem presente o que neste admirável filme ${ }^{8}$ se conta. Trata-se da história de uma figura bizarra, alegadamente atingida por uma perturbação psicopatológica que explica o epíteto de homem-camaleão que lhe é atribuído: manifestava-se em Leonard Zelig a tendência para se desdobrar e mimeticamente replicar aquele ou aqueles com quem interagia, naquilo que parecia ser um culto irreprimível da alteridade, atentamente seguido por uma psiquiatra (Dra. Eudora Fletcher); é ela quem tenta a cura desse paciente por quem depois se apaixona. O físico, a linguagem, a indumentária e a gestualidade de Zelig traduziam, de forma algo burlesca, aquela tendência, vivida num contexto histórico particular: o final dos anos 20 e os anos 30, tempo marcado pela depressão da economia norte-americana, na sequência do crash bolsista de 1929, pela ascensão do nazismo e pelo pontificado de Pio XI (1922-1939).

A construção narrativa do filme está dominada por várias estratégias enunciativas. Primeiro: o recurso a uma voz over anónima, numa instância de narração exterior à história, atribuível a um narrador omnisciente e potencialmente fiável. Segundo: uma configuração genológica intermediática e internarrativa, que articula os registos

\footnotetext{
${ }^{8} \mathrm{Na}$ receção que Zelig conheceu, à época em que foi produzido e exibido, contam-se nomeações para prémios de grande destaque (Oscar da Academia, Globo de Ouro e BAFTA), mas nenhuma atribuição efetiva.
} 
do documentário, da reportagem jornalística, da biografia cinematográfica (o chamado "biopic film") e da narrativa historiográfica. Terceiro: a centralidade de Zelig como figura em torno da qual gira todo o relato, centralidade expressa logo no título do filme. Quarto: a oscilação entre procedimentos de veridicção ${ }^{10}$, acentuando a alegada veracidade da figura, e procedimentos de desmontagem desse estatuto, sempre que se põe em causa a mais elementar verosimilhança (por exemplo: de regresso aos Estados Unidos, Zelig pilota um avião que atravessa o Atlântico de cabeça para baixo).

Aquela oscilação gera uma ambivalência que domina todo o filme, afirmando-se como sua decisiva marca identitária. Vale a pena insistir no significado dos estratagemas que servem para construir discursivamente a pseudo-veracidade de Zelig. Antes de mais e logo a abrir o filme: a incorporação narrativa de depoimentos com propósito legitimador. Personalidades destacadas da vida intelectual norte-americana, como Susan Sontag, Irving Howe, Saul Bellow ou Bruno Bettelheim aparecem a dar testemunhos autorizados a propósito do fenómeno Zelig. Para além disso, as várias trucagens sofridas por supostos documentos cinematográficos "de época" reforçam a dimensão histórica e não ficcional de Zelig. A mais evidente dessas trucagens é a que confere aspeto desgastado às películas, com aparência de documentários ou noticiários cinematográficos muito antigos, que ilustram episódios da vida de Zelig, bem como acontecimentos históricos por ele vividos; não menos expressivo (mas porventura excessivo e, por isso, já com feição desconstrutiva e mesmo paródica) é o aparecimento de Zelig ao lado do escritor Scott Fitzgerald e sobretudo o modo como irrompe num comício

\footnotetext{
9 A expressão "biopic film" é uma redução de "biographical pictures" e refere-se a filmes que relatam a biografia de figuras com relevo histórico ou cultural, eventualmente com interpretações e extensões de índole ficcional.

${ }^{10}$ Retomo aqui o conceito semiótico de veridicção como manifestação do dizer-verdade apoiada em ilusões referenciais, processo discursivo dependente de uma conceção imanente da linguagem.
} 
de Hitler, perturbando o discurso do Fürher. E ainda: a alternância da cor com o preto e branco (que Allen voltou a usar em $A$ Rosa Púrpura do Cairo) reforça a diferença entre o passado (preto e branco) e o presente (cor); sendo assim, a Eudora Fletcher do presente não está apenas muito mais velha (e por isso não pode ser interpretada pela mesma Mia Farrow do passado a preto e branco), como também é filmada a cores.

O confronto com esta construção veridictiva e também o seu reforço são estabelecidos pelo recurso a um outro documento de época, este citado como uma ficção. Trata-se do filme The Changing Man, apresentado como uma produção da Warner Brothers, de 1935, que pretende ser a reconstrução ficcional do "caso" Zelig. Por comparação com a elaboração documental e mesmo historiográfica que domina a biografia de Leonard Zelig, o filme da Warner revela-nos uma figura idealizada, o que se acentua ainda pela retórica interpretativa do ator a quem cabe o papel de Zelig. O comício de Munique, em que Eudora reencontra Leonard, permite observar o contraste entre as duas versões; para mais, a segunda é desautorizada por Eudora, que claramente afirma que aquilo que de facto se passou não foi nada parecido com o que vê no filme. E assim, pelo "excesso" da ficção, reforça-se a "autenticidade" daquilo que nos é proposto como evocação de um caso verídico.

5. Trato agora de alargar o que anteriormente foi analisado, no sentido de, em movimento de transnarrativização, tentar identificar três princípios constitutivos do conhecimento narrativo sugeridos por Zelig. Um conhecimento que julgo ser indissociável do reconhecimento da narrativa como tal, dos seus protocolos enunciativos e das suas formulações figuracionais; incidem estas últimas sobre a personagem como categoria central do relato, em direta relação com o sentido humano que nele se elabora. Refiro-me, assim, a três princípios que estruturam a composição de Zelig. 
5.1. Primeiro princípio, o da credibilidade narrativa. Num largo trajeto que vai das poéticas da Antiguidade até às primícias da modernidade, a verosimilhança impõe-se como critério de aceitabilidade e de integração cognitiva da narrativa e em particular da narrativa literária. A credibilidade que pela verosimilhança se estabelece requer, naturalmente, aquela suspensão voluntária da descrença a que já aludi e que pode ser entendida, por outro lado, como uma afirmação de crença no poder evocativo e representacional da palavra literária ${ }^{11}$. Foi esse poder que deu lugar aos realismos e ao seu propósito de narrativizar, normalmente com intuito crítico, situações, conflitos e figuras que nos dão a conhecer tempos e estados das sociedades a que aqueles realismos se reportam. ${ }^{12}$

As poéticas do modernismo e do pós-modernismo não desvalorizaram, bem pelo contrário, o princípio da credibilidade narrativa, mas reajustaram-no em função de uma nova episteme do sujeito, que é proposta pelo pensamento literário e filosófico de Mallarmé e de Nietzsche, de Freud, de T. S. Eliot e de Fernando Pessoa, entre outros. Essa nova episteme, correspondendo também a uma crise do sujeito, cultiva uma retórica da veridicção que assenta na força performativa de atos discursivos literários e metaliterários e na aquisição do desdobramento como evidência daquela crise (o Ultimatum de

\footnotetext{
${ }^{11}$ Recorde-se que, no passo da Biographia Literaria (1817) em que exarou aquele famoso conceito, Coleridge falou também em fé poética. Assim: "That willing suspension of disbelief for the moment, which constitutes poetic faith." (em http://www. english.upenn.edu/ mgamer/Etexts/biographia.html; acesso a 2.1.2016).

${ }^{12}$ São conhecidos os termos em que Engels, numa carta de abril de 1888 (e apesar de diferenças ideológicas que assinala), fez o elogio de Balzac como romancista que retratou a sociedade francesa posterior a 1815. "He describes how the last remnants of this, to him, model society gradually succumbed before the intrusion of the vulgar monied upstart, or were corrupted by him"; e mais adiante: "And around this central picture he groups a complete history of French Society from which, even in economic details (for instance the rearrangement of real and personal property after the Revolution) I have learned more than from all the professed historians, economists, and statisticians of the period together." (carta a Margaret Harkness, em https://www. marxists.org/archive/marx/ works/1888/letters/88_04_15.htm ; acesso a 2.1.2016).
} 
Álvaro de Campos é, neste contexto, um testemunho admirável de força expressiva e nietzschiana).

A construção da heteronímia pessoana é consabidamente um marco relevante a assinalar aquele percurso de mutações ontológicas e epistemológicas. É bem sintomático, aliás, que a sua conceção como drama em gente envolva a noção de personagem (é assim que Pessoa designa os heterónimos), num processo cuja feição paranarrativa parece evidente, muito antes de isso ser confirmado na famosa carta de 1935 a Adolfo Casais Monteiro sobre a génese dos heterónimos ${ }^{13}$. Ao mesmo tempo, não podemos ignorar que a síndrome Zelig e as atribulações do homem-camaleão manifestam-se naqueles anos 30 em que Pessoa ia refinando e aprofundando a sua encenação heteronímica. ${ }^{14}$ Nesse tempo propício a tais aventuras, insinua-se em ambos a credibilidade narrativa como fator de consolidação de trajetos existenciais autónomos; o sentido que nesses trajetos lemos é potenciado justamente por uma naturalização narrativa que lhes dá consistência própria.

É claro que, em Zelig, a credibilidade narrativa desliza (e de certa forma desvanece-se) para uma certa derrisão que nos desdobramentos modernistas escassa ou nulamente transparece. Se o homem-camaleão viveu nos anos 20 e 30 em que a aventura pessoana e outras

\footnotetext{
${ }^{13}$ Num dos seus mais conhecidos textos de reflexão metaliterária, escreveu Pessoa que, "se analisarmos bem aquilo de que se [os géneros] se compõem, verificaremos que da poesia lírica à dramática há uma gradação contínua. Com efeito, e indo às mesmas origens da poesia dramática - Ésquilo por exemplo - será mais certo dizer que encontramos poesia lírica posta na boca de diversos personagens." E noutro passo: "Por qualquer motivo temperamental que me não proponho analisar, nem importa que analise, construí dentro de mim várias personagens distintas entre si e de mim, personagens essas a que atribuí poemas vários que não são como eu, nos meus sentimentos e ideias, os escreveria." (Pessoa, s.d.)

${ }^{14}$ Para além disso, a construção da teoria poética pessoana coincide, em boa parte, com o tempo de desenvolvimento da teoria do romance e da filosofia da linguagem bakhtinianas (Problemas da poética de Dostoievski é de 1929 e O discurso no romance é de 1934-35). Não surpreende, por isso, que os conceitos de pluridiscursividade, de polifonia e de alteridade possam ser relacionados, como já aconteceu, com o universo pessoano e, já agora, com a síndrome Zelig. Cf. Reis, 1989 e, na sequência deste, Vila Maior, 1994.
} 
similares se desenvolveram, a sua conceção, a produção e a realização cinematográfica que lhe deram vida revelam uma marca pós-modernista que é já de outro tempo: com Zelig, estamos agora naqueles anos 80 em que o cinema de Woody Allen se deixou seduzir pelos jogos metaficcionais que encontramos também n'A Rosa Púrpura do Cairo e n'Os Dias da Rádio. Nestes, como em Zelig, a metalepse e a desconstrução paródica são desafios que não dispensam, por vezes, a citação de outras ficções, retomadas no contexto de derrisão que agora está em causa. Não é destituído de significado o facto de Zelig aparecer fotografado como Canio, o ator-palhaço; o desdobramento convoca, neste caso, uma personagem que, na ópera Pagliacci de Leoncavallo, vive dramaticamente a tensão de quem oscila entre a condição de ator e a personagem (Pagliaccio) que ao mesmo tempo vive e rejeita ${ }^{15}$.

5.2. Falo agora do princípio da transhistoricidade, de novo deduzido do que observamos em Zelig; e relaciono-o, antes de mais, com a reconhecida e ancestral vocação da narrativa para dialogar com a História e mesmo para nela interferir. Nesse sentido, a narrativa pode tematizar explicitamente a História (p. ex.: o romance histórico), interagir com ela, propor uma sua interpretação ou até questionar subversivamente heróis e episódios que a historiografia convencional configurou.

É em função do princípio da transhistoricidade que lemos a História no relato ficcional: ele transcende, refaz e prolonga no tempo o passado visado pela História e quem nele habitou, fazendo-o chegar até nós sob forma narrativa. Mais: sem descurar, antes reforçando, a sua dimensão ideológica (e mesmo, por vezes, pedagógica), a narrativa

\footnotetext{
${ }^{15}$ Aquilo a que chamo tensão entre ator e personagem foi glosado, no quadro da encenação dramática propriamente dita e do tratamento do casting, em Balas sobre a Broadway, um filme que, mais do que Zelig, merece um confronto com a ópera mencionada e também, já agora, com Sei personaggi in cerca d'autore, de Pirandello.
} 
ficcional chega a reescrever a História, entendendo-a como imagem precária e suscetível de ser discursivamente superada ${ }^{16}$.

Numa sequência de Zelig, construída com a ajuda de um (pseudo) documentário noticioso onde se nota a patine que o tempo depositou na película cinematográfica, vemos o protagonista numa cena passada em Roma, num Domingo de Páscoa. Nela, Leonard Zelig aparece inopinadamente ao lado de Pio XI e perturba a cerimónia da bênção papal urbi et orbi; perante milhares de fiéis, instala-se então a confusão na varanda principal da Praça de São Pedro, ao ponto de o papa agredir o intruso. Por seu lado, o já citado comício de Munique suscita, muitos anos depois, o comentário de uma testemunha presencial: Oswald Pohl, de quem, em legenda, se diz ser um antigo membro das SS nazis, reconhece que Zelig interferiu no discurso de Hitler, impedindo-o de dizer uma piada sobre a Polónia.

Que o excesso e o absurdo sejam dominantes em ambos os episódios é algo que pouco importa agora. O que interessa é a sugestão que fica: a narrativa, neste caso cultivando uma ambivalência que a faz oscilar entre a lógica do ficcional e a retórica do documental, impõe-se como dispositivo capaz de, conforme escreveu José Saramago, introduzir na História aqueles "pequenos cartuchos que façam explodir o que até então parecia indiscutível". Preside a esse ato aquilo que se apresenta ao grande romancista (e, como se sabe, admirável cultor de ficções metahistoriográficas com intuito ideológico) como "a consciência da nossa incapacidade final para reconstituir o passado" (Saramago, 1990: 19) ${ }^{17}$. Por isso, Saramago concebeu "pequenos cartuchos" chamados Blimunda e Baltasar Sete-Sóis, parentes e cúmplices

\footnotetext{
${ }^{16}$ Aproximo-me aqui das teses de Hayden White (White, 1978: 81-99).

${ }^{17}$ Não se trata, para Saramago, de corrigir ou de reescrever infinitamente a História. Mas é o romancista quem pode empreender uma "espécie de reivindicação ou o ato de chamar à presença", de "reclamar a presença" da História na narrativa que a questiona. (Reis, 2015a: 89).
} 
de Leonard Zelig que, à sua maneira burlesca, nos fez conhecer em Pio XI e em Adolf Hitler comportamentos inusitados. E assim, num outro medium e em tom paródico, o homem-camaleão reafirma o direito (e o poder) que a narrativa reclama para incessantemente reescrever o que por outra narrativa, a da História, fora dito.

5.3. Como se viu, a personagem é um elemento capital da manifestação das virtualidades de tratamento transhistórico que a narrativa encerra. Por isso mesmo, o princípio da figuratividade constitui um fator relevante (e último, por agora) de concretização do conhecimento viabilizado pela narrativa.

Designo aqui por figuratividade a propriedade ou conjunto de propriedades que decorrem dos dispositivos de modelização da personagem como figura ficcional; e chamo genericamente figuração a esses dispositivos e ao seu trabalho narrativo. Retomando o que escrevi noutro local, a figuração pode ser entendida como "um processo ou um conjunto de processos constitutivos de entidades ficcionais de feição antropomórfica, conduzindo à individualização de personagens em universos específicos, com os quais essas personagens interagem" (Reis, 2015b: 121-122 $)^{18}$.

$\mathrm{O}$ caso Zelig e a forma como é narrativamente representado revela-se-nos um contributo significativo para apurarmos alguns aspetos do mencionado princípio da figuratividade, enquanto componente que colabora na estruturação do relato. Com Zelig e, mais alargadamente, com a figuração da personagem é pelo nome que

\footnotetext{
${ }^{18}$ Acrescento ao que fica dito: "Tal individualização verifica-se sobretudo em contextos narrativos e em contextos dramáticos, mas acontece, igualmente de modo residual, em contextos de enunciação poética; passa-se isto, em especial, quando estão em causa composições dotadas de um certo índice de narratividade. Ou seja: a personagem pode ser figurada na poesia lírica. Por outro lado, a figuração deve ser encarada em aceção translata, quando observamos a sua ocorrência em discursos que não são formal ou institucionalmente literários. Refiro-me, por exemplo, à historiografia, à epistolografia e aos discursos de imprensa (p. ex., os retratos de figuras públicas, os obituários, etc.)." (Reis, 2015b: 122)
} 
tudo começa. Ou melhor, pela sua procura, como se a personagem fosse (e de facto é) uma entidade dinâmica, parecendo o próprio nome, nas primeiras abordagens, um componente em movimento: Leon Selwin ou Zelman são as denominações anotadas pelo romancista Scott Fitzgerald, primeira testemunha convocada para, logo no início do relato, dar a conhecer a figura que vai ser biografada. Sintomaticamente, é pelo registo de um ficcionista que essa figura começa a tomar forma e condição humana. Mais: a voz over do narrador lembra que, como romancista, foi Fitzgerald quem registou os anos 20 da vida norte-americana para as gerações futuras. Fica assim exarado um atestado de autoridade que, ao mesmo tempo que confere credibilidade ao caso em desenvolvimento, traz à cena da narrativa o trabalho de um ficcionista, em cuja esfera de ação ambiguamente Zelig é colocado.

As variações sobre o nome (quando aparece num treino dos Yankees, o jogador desconhecido chama-se agora Lou Zelig) não são inconsequentes. Elas anunciam outras variações, mais complexas e mais problemáticas, assim se insinuando aquele que é um modo de caracterização por vezes presente na figuração da personagem: a relação de coerência entre o nome (neste caso, a sua indefinição inicial) e a personalidade.

As mencionadas variações são o fulcro da identidade mutável de Zelig. Mimetizando constantemente o outro com quem interage, Zelig é uma figura em incessante busca e reconstrução, assim se sugerindo que o conhecimento da personagem é, de forma correlata, um processo sempre em aberto. $\mathrm{O}$ que bem pode ser confirmado, num outro plano de análise, por quem nos diz que "o conceito de personagem já não é um conceito estático" (Felski, 2011: V), a isto podendo acrescentar-se o seguinte: "Sem dúvida, uma certa conceção do que constitui uma personagem - uma ideia de personalidade unificada, imutável, intrínseca ou impermeável - já não é sustentável em bases teóricas ou históricas" (Felski, 2011: IX). 
6. Para terminar: o processo de narrativização a que assistimos em Zelig depende, em grande parte, de reconhecermos como narrativa aquilo que o é, com base na nossa experiência de produtores e de consumidores de relatos, desde os do nosso quotidiano até às ficções mais elaboradas. Os princípios que descrevi (da credibilidade, da transhistoricidade e da figuratividade) contribuem para refinar culturalmente a funcionalidade das narrativas, ao mesmo tempo que requerem uma competência de leitura a que podemos chamar literacia narrativa.

É a nossa literacia narrativa que recorrentemente é interpelada por Zelig. Acontece assim sobretudo quando nos damos conta daquela ambivalência de que anteriormente falei e que é instaurada por uma certa hibridização de procedimentos: discursos e estratégias veridictivas convivem e alternam com o excesso da paródia que desmistifica a "autenticidade" histórica da figura e dos episódios que ela vive.

$\mathrm{O}$ casting e as suas exigências colaboram naquela hibridização. Começamos a ver aquilo que, por força de vários estratagemas retóricos, tem a aparência de um documentário, mas logo nos apercebemos de que a figura central dessa biografia documentada e atestada por várias formas é interpretada por um ator que conhecemos: Woody Allen. Logo de seguida, a Dra. Eudora Fletcher (mencionada na abertura do filme como destinatária de agradecimentos, como é usual em documentários) tem o rosto da atriz Mia Farrow.

Estaria desfeita, logo deste modo, a tal ambivalência (o casting "diz-nos" que, afinal, o filme conta uma ficção, pela interpretação de atores conhecidos), se não se desse o caso de, pouco depois, aparecer, a cores, a Dra. Eudora Fletcher envelhecida mas não identificável com nenhuma atriz conhecida. Quero dizer, como se se tratasse de uma pessoa real, no mesmo plano ontológico de Susan Sontag, de Saul Bellow ou de Bruno Bettelheim. Acentua-se esta tentativa de recuperar a veridicção pelo facto de aquele papel de Eudora-envelhecida ser desempenhado (afinal, alguém tinha de o fazer...) por Ellen 
Garrison, que nunca fora (nem voltou a ser) atriz na sua vida ${ }^{19}$. Nada disto se confunde, note-se, com a mais convencional situação do biopic film: aqui, sem trucagens nem ambiguidades, um ator encarna uma personalidade real, num registo desde logo reconhecido como o de um filme biográfico com propósito artístico e, não raro, com derivações ficcionais (por exemplo: Daniel Day-Lewis fazendo de Abraham Lincoln ou Philippe Seymour Hoffman de Truman Capote).

No fim de contas, Zelig deixa-nos várias interrogações, perversamente induzidas pelos jogos metaficcionais que nele se desenrolam. Uma dessas interrogações: não será próprio de toda a narrativa o culto daquela espécie de vacilação entre o testemunho que afirma o verídico e a tentação pela ficção? Outra questão: não caberá à narrativa resolver a ordenação do que é disperso e a integração daquilo que tem proveniência díspar (ou seja: entidades reais e entidades ficcionais)? Não será essa vocação integradora a via para se atingir um superior sentido narrativo, como objetivo último que motiva a enunciação de relatos? Um sentido que, na linha do pensamento de Paul Ricoeur, se distingue pela sua dimensão humana ou, num quadro de referência antropológica, como algo em que reconhecemos dimensão transcultural. E uma última interrogação, ainda a partir de Zelig: em que medida o poder representacional da imagem aprofunda (e também torna mais complexa) a tendência da narrativa para cultivar a oscilação entre o ficcional e o verídico, para integrar o que é disperso e para, desse modo, atingir o tal sentido narrativo que é a ultima ratio de todo o relato?

Serão perguntas retóricas? Se esta reflexão continuar, tratarei de resolver esta última interrogação - que, para que conste, nada tem de retórico.

\footnotetext{
${ }^{19}$ Ellen Garrison, que foi presidente da Women United for the United Nations, tinha 83 anos quando apareceu em Zelig e veio a falecer em 1995. Veja-se o obituário que sobre ela foi publicado no New York Times, em http://www.nytimes.com/1995/06/06/ obituaries/ellen-garrison-96-acted-in-film-zelig.html (acedido a 4.1.2016).
} 


\section{REFERÊNCIAS BIBLIOGRÁFICAS}

ABBOTT, H. P. (s.d.). "Narrativity", in The Living Handbook of Narratology (em http:// www.lhn.uni-hamburg.de/article/narrativity ; acedido a 7.1.2015).

BARTHES, R. (1966). "Introduction à l'analyse structurale du récit”, in Communications, 8, pp. 1-27.

BRUNER, J. (1991). "The narrative construction of reality", in Critical Inquiry, vol. 18, 1, pp. 1-21.

FELSKI, R. (2011). "Introduction", in New Literary History, 42: 2, pp. v-ix.

FLUDERNIK, M. (1996). Towards a 'Natural' Narratology. London and New York: Routledge.

PESSOA, F. (s.d.) "Dividiu Aristóteles a poesia em lírica, elegíaca, épica e dramática", em http://arquivopessoa.net/textos/4306 (acedido a 7.1.2016).

PRINCE, G. (2003). A Dictionary of Narratology. Revised edition. Lincoln and London: The Univ. of Nebraska Press.

PRINCE, G. (2005). "Narrativity", in D. Herman et alii (eds.), Routledge Encyclopedia of Narrative Theory. London and New York: Routledge, pp. 387-388.

QUEIRÓS, E. de (2009). Cartas Públicas. Edição de Ana Teresa Peixinho. Lisboa: Imprensa Nacional-Casa da Moeda.

REIS, C. (1989). "Les hétéronymes de Pessoa et la théorie bakhtinienne du dialogisme", in Manfred Pfister (ed.), Die Monernisierung des Ich. Passau: Wissenschaftsvrelag Richard Rothe, pp. 306-311.

REIS, C. (2015). Diálogos com José Saramago. 2. ${ }^{a}$ ed. Porto: Porto Editora.

REIS, C. $\left(2015^{\text {b }}\right)$. Pessoas de livro. Estudos sobre a personagem. Coimbra: Imprensa da Universidade de Coimbra.

REIS, C. e A. C. M. LOPES (2011). Dicionário de Narratologia. $7^{\mathrm{a}}$ ed. Coimbra: Almedina.

RICOEUR, P. (1983). Temps et récit. Paris: Seuil, tomo I.

RYAN, M.-L. (ed.) (2004). Narrative across Media. The Languages of Storytelling. Lincoln and London: Univ. of Nebraska Press.

RYAN, M.-L. (2006). Avatars of Story. Minneapolis and London: Univ. of Minnesota Press. 
RYAN, M.-L. e J.-N. THON (eds.) (2014). Storyworlds across Media. Toward a MediaConscious Narratology. Lincoln and London: Univ. of Nebraska Press.

SARAmAgO, J. (1990). "História e ficção", in Jornal de Letras, Artes e Ideias, 6 de março de 1990, pp. 17-19.

VILA MAIOR, D. (1994). Fernando Pessoa: heteronímia e dialogismo. Coimbra: Almedina.

WHITE, H. (1978). Tropics of Discourse. Essays in Cultural Criticism. Baltimore: The Johns Hopkins University Press. 